\title{
Research on Effect of Ventilated Region to Grape Rain Shed Performance Based on CFD
}

\author{
Jian Wang ${ }^{1}$ and Hongbing Yang ${ }^{2, *}$ \\ ${ }^{1}$ College of Horticulture, Nanjing Agricultural University, Nanjing, China 210095 \\ ${ }^{2}$ College of Engineering, Nanjing Agricultural University, Nanjing, China 210031 \\ \{wangjian, hbyang\} @njau . edu.cn
}

\begin{abstract}
Two different kinds of multi-span grape rain sheds are constructed and the wind field and rainfall field distribution are simulated based on CFD and computer simulation techniques. The airflow distribution, temperature variation, wind pressure distribution and rainfall vectors distribution are compared under two conditions with ventilated region and without ventilated area in multi-span grape rain shed. The research results show that set the ventilated area on the top of grape rain shed can improve effectively the high temperature and high humidity climate environment, and it has a benefit to grapes fertility.
\end{abstract}

Keywords: CFD, Multi-span grape rain shed, ventilated region, simulation.

\section{Introduction}

Rainproof cultivation is one important form of grape protected cultivation in southern China. Grape rainproof cultivation has two main merits. On the one hand, the grape fruit set is promoted, and the grape quality is improved. On the other hand, the soil moisture is controlled effectively, and the fungus spread and the amount of pesticide spraying are decreased significantly [1]. However, under the effects of the temperature rise rapidly and grape transpiration, the temperature and humidity are very high on the top of grape rain shed during May to July, and it can be damaged the grape fruit set. If the ventilated region is set on the top of shelter shed, the high temperature and humidity conditions may be improved. Nevertheless, the construction of grape rain shed is changed when ventilated area is set, and the climate environments of shelter shed how to change when ventilated region is set. These new problems need to be researched in detail. In recent years, the computer simulation techniques have a wide range of applications in agricultural facilities. Briassoulis and Mistriotis [2] proposed the integrated structural design methodology for agricultural protecting structures covered with nets based on computer simulation method. Harmanto [3] simulated the airflow distribution of greenhouse under different mesh sizes of nets and predicted the air exchange rate. M. Teitela[4]researched the effect of

${ }^{*}$ Corresponding author. 
wind direction on greenhouse ventilation rate, airflow patterns and temperature distributions based CFD.

The aims of this research were to analysis the effect of ventilated region to climate environment, and evaluate the possibility of installing ventilated region in the grape rain shed. The airflow distribution, temperature variation, wind pressure distribution and water vectors distribution are compared under two conditions of ventilated region and non-ventilated area in grape rain shed.

\section{Material and Method}

\subsection{Grape Multi-span Greenhouse}

The grape multi-span greenhouse was located in the coastal areas of Jiangsu province. The multi-span grape rain shed is built by a new kind of coated PE plastic steel pipe and the schematic diagram is shown in figure 1a. The four-span greenhouse (length is $12 \mathrm{~m}$ and height is $2.374 \mathrm{~m}$ ) is covered with polyethylene film. One meter wide vent is set each two spans on the top of multi-span grape rain shed. The schematic diagram with ventilated region is shown in figure $1 \mathrm{~b}$.

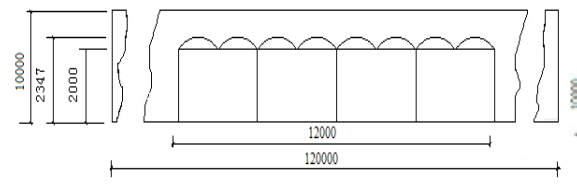

(a) without ventilated region

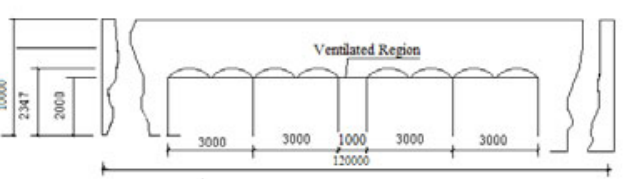

(b) with ventilated region

Fig. 1. Schematic diagram multi-span grape rain shed (mm)

Wind pressure formula [5] is give by

$$
p_{v}=\frac{1}{2} C \rho_{a o} v_{0}^{2}
$$

Where $C$ is pressure shape factor, $\rho_{a o}$ is outdoor air density $\left(\mathrm{kg} / \mathrm{m}^{3}\right)$ and $v_{0}$ is outdoor wind speed $(\mathrm{m} / \mathrm{s})$.

Boulard and Baille $[6,7]$ put forward the ventilation rate formula. When only considering the role of wind pressure, the ventilation rate $G$ is

$$
G=(S / 2) A C_{w}^{0.5} \bar{v}
$$

Where $\mathrm{S}$ is vent cross-sectional area $\left(\mathrm{m}^{2}\right)$, A is vent distribution coefficient, $C_{w}$ is wind pressure effect coefficient and $\bar{v}$ is average wind speed $(\mathrm{m} / \mathrm{s})$. 


\subsection{CFD Numerical Simulation Method}

Computational fluid dynamics (CFD) is a sophisticated design and analysis tool that allows us to study different design limitations based on a computational model. The CFD software used in the present work was FLUENT 6.2. Its code uses a discretization procedure of finite volumes and it incorporates the equations that govern heat flow and transfer, such as the continuity equation, momentum conservation and energy conservation. The overall methodology used to carry out a complete study with the commercial software used in this work is summarized as follows: generating the geometry of the fluid domain, meshing, defining the boundary conditions and the physical properties of the model (pre-processing), solving and finally analysis (post-processing) [8]. The classical mass, momentum, energy and concentration equations can be represented for a steady-state, three-dimensional flow with the following conservation equation.

$$
\frac{\partial \phi}{\partial t}+\frac{\partial}{\partial x_{j}}\left(u_{j} \phi\right)=\frac{\partial}{\partial x_{j}}\left(\Gamma_{\phi} \frac{\partial \phi}{\partial x_{j}}\right)+S_{\phi}
$$

Where $\Phi$ stands for the variables of interest, i.e. the three velocity components $\mu_{\mathrm{j}}\left(\mathrm{ms}^{-1}\right)$, the temperature $\mathrm{T}(\mathrm{K}), \Gamma_{\Phi}$ and $\mathrm{S}_{\Phi}$ represent the diffusion coefficient and source term of $\Phi$ and a description of their forms can be found in Boulard [9-10]. The system of equations built with these variables is numerically solved with the finite volume method. Algorithms and methods for the resolution of this system of equations can be found in the fluent 6.2 user's guide. To model the turbulent constraints using the standard $\mathrm{k}-\varepsilon$ turbulence model, in Eq. $1 \Phi$ stands also for the turbulent kinetic energy $\mathrm{k}\left(\mathrm{m}^{2} \mathrm{~s}^{-2}\right)$ and the dissipation of the turbulent kinetic energy $\varepsilon\left(\mathrm{m}^{2} \mathrm{~s}^{-3}\right)$.

The airflow field and rain field of multi-span grape rain shed are researched differently. The airflow field distribution is simulated when the wind direction is 0 degree, wind velocity is $20 \mathrm{~m} / \mathrm{s}$ and temperature is $308 \mathrm{~K}$. The rain field distribution is researched when rain direction 0 degree, rain velocity is and $5 \mathrm{~m} / \mathrm{s}$ and temperature is $308 \mathrm{~K}$.

\section{Results and Discussion}

\subsection{Airflow Distribution Simulation of Multi-span Grape Rain Shed Based on CFD}

Wind pressure distribution contours of two kinds of multi-span grape rain shed are shown in figure 2. From figure 2 we can see that outer surface of two different kinds of shelter sheds are lift state under the action of wind pressure, and their external flow field distribution is almost the same. However, the internal flow field of two kinds of rain shelters is different. The flow field distribution of span 1 and 2 with ventilated 


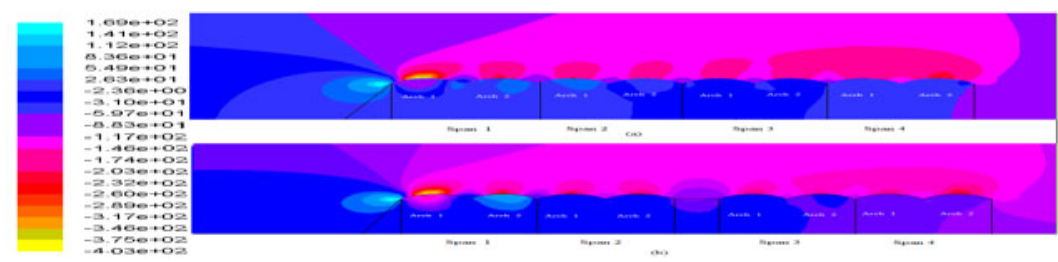

Fig. 2. Pressure distribution contours of two kinds of grape rain sheds

region is uniform, and the flow field distribution of span 3 and 4 with ventilated region is more uneven than non-ventilated region.

The wind pressure distribution on the top of shelter shed is given in figure 3 . The abscissa axis represents the span of grape rain shed, and the ordinate axis stands for the wind pressure distribution. It can be seen that the wind pressure distribution of Span 1 and span 2 is similar to two different kinds of grape rain shed. The wind pressure distribution of span 3 and span 4 is different to two different kinds of grape rain shed. From figure 3(a) we can know that the top of shelter shed is lift mainly. The wind lift maximal is $370 \mathrm{~Pa}$ and wind pressure maximal is $72 \mathrm{~Pa}$ in the span 1 and span 2, and from Span 3 to span 4, the value range of wind of upward lift is $10 \sim 189 \mathrm{~Pa}$. It can be seen from figure 3(b) that wind lift maximal is $354 \mathrm{~Pa}$ and wind pressure maximal is $216 \mathrm{~Pa}$ in the span 1 and span 2, and from Span 3 to span 4 , the value range of wind pressure is $0 \sim 74 \mathrm{~Pa}$. Simulation results show that the wind pressure value is decreased on the top of grape rain shed when the ventilated region is installed. According to formula (1)we can see that it is proportional relationship between wind speed and air pressure, So the wind speed is decreased, the wind pressure is also decreased. The airflow velocity vectors distribution of multi-span grape rain shed with ventilated region is shown in figure 4 . When the ventilated region is set, the velocity of external grape rain shed is decreased, so the wind pressure value is decreased correspondingly.

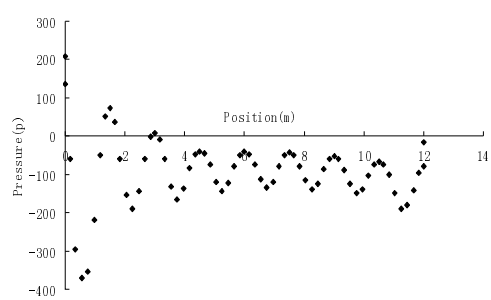

(a) without ventilated region

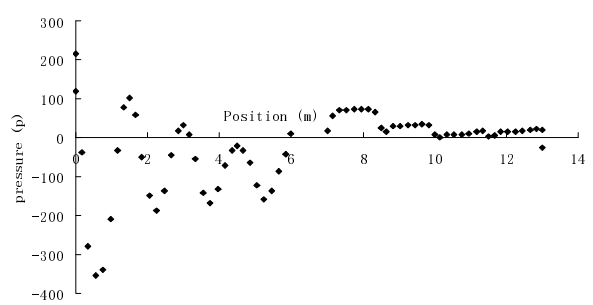

(b) with ventilated region

Fig. 3. Pressure distribution curve on the top of grape rain shed 


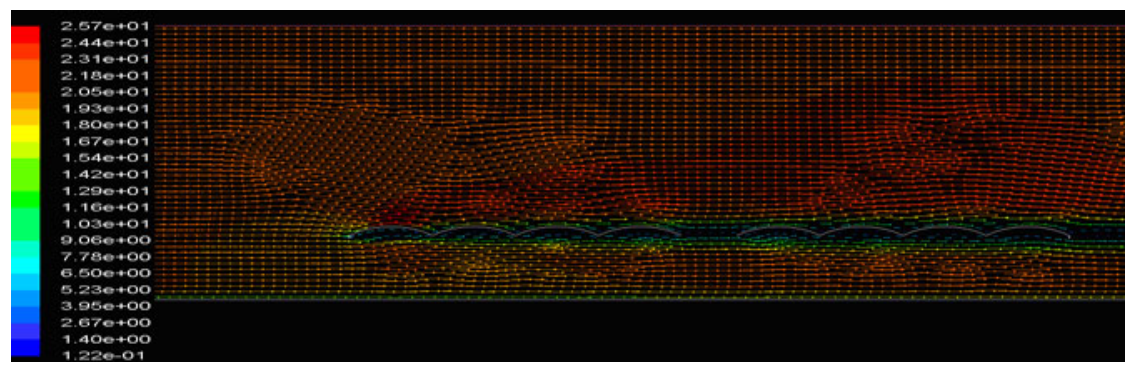

Fig. 4. Velocity vectors distribution of multi-span grape rain shed with ventilated region

\subsection{Temperature and Rainproof Performance Simulation of Multi-span Grape Rain Shed Based on CFD}

The internal temperature distribution of two different shelter sheds is shown in figure 5. It can be seen that the inner temperature of grape rain shed with ventilated region is

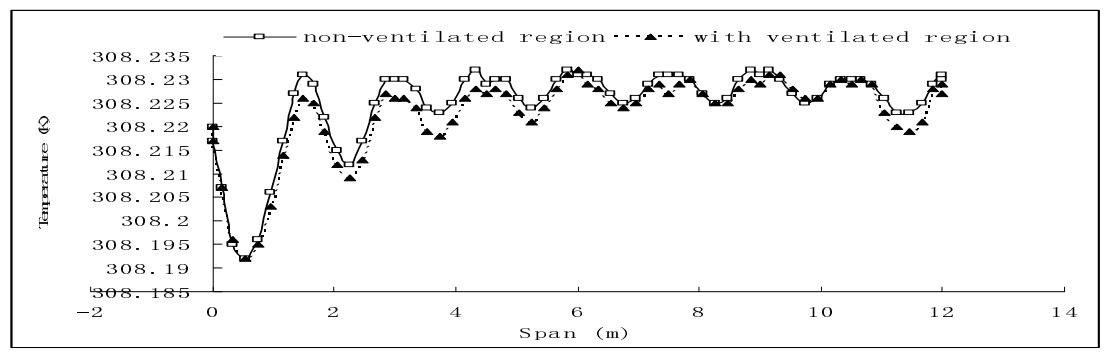

Fig. 5. Internal Temperature distribution of two different shelter sheds

(a) without ventilated region

(b) with ventilated region

Fig. 6. Rainfall vector distribution of two different grape rain shed

decreased significantly. This is consistent with formula (2), and when the internal wind speed is increased, the ventilation rate is increased accordingly, so temperature and humidity of grape rain shed with ventilated region are deceased clearly. The rainproof performance has some impact when the ventilated region is set in grape rain shed. When rainfall vertical ground and the velocity is $5 \mathrm{~m} / \mathrm{s}$, the rainproof effect of two kinds of grape rain shed is simulated in figure 6. Compared figure 6(a) and 
figure 6(b), we can see that the rainproof performance without ventilated region is better than grape rain shed with ventilated region. However, it can be seen that rainfall distribution mainly at the near ground in grape rain shed clearly and these rainfall has little effect on the grape growth.

\section{Summary}

The two kinds of models of grape rain shed are constructed, and the airflow distribution, temperature variation, wind pressure distribution and rainfall vectors distribution are compared under two conditions of ventilated region and nonventilated area in grape rain shed based on computer simulation. The research results show that set the ventilated area on the top of grape rain shed can improve effectively the high temperature and high humidity climate environment, and it has a benefit to grapes fertility. Of course, the construction costs of grape rain shed is increased when installing ventilated region.

Acknowledgments. This work has been funded by Doctoral Fund of Ministry of Education (No.20090097120014).

\section{References}

1. Li, J.C., Shun, D.L., Zhang, X.S.: Effect of rainproof cultivation on grape disease incidence and light intensity under the shelter. Journal of Fruit Science 26(6), 847-850 (2009)

2. Briassoulis, D., Mistriotis, A.: Integrated structural design methodology for agricultural protecting structures covered with nets. J. Biosystems Engineering 105, 205-220 (2010)

3. Harmanto, H., Tantau, J., Salokhe, V.M.: Microclimate and air exchange rates in greenhouses covered with different nets in the humid tropics. J. Biosystems Engineering 94(2), 239-253 (2006)

4. Teitel, M., Ziskind, G., Liran, O., et al.: Effect of wind direction on greenhouse ventilation rate, airflow patterns and temperature distributions. J. Biosystems Engineering 101(3), 351-369 (2008)

5. Zhou, C.J.: Modern Greenhouse Engineering. Publishing House of Chemistry and Industry, Beijing (2003)

6. Boulard, T., Baille, A.: Modeling of air exchange rate in greenhouse equipped with continuous roof vents. Journal of Agricultural Engineering Research 61(1), 37-48 (1995)

7. Boulard, T., Feuilloley, P., Kittas, C.: Natural Ventilation Performance of Six Greenhouse and Tunnel Types. Journal of Agricultural Engineering Research 67(4), 249-266 (1997)

8. Franco, A., Valera, D.L., Pena, A., Pérez, A.M.: Aerodynamic analysis and CFD simulation of several cooling pads used in Mediterranean greenhouses. J. Computers and Electronics in Agriculture 76(2), 218 (2011)

9. Bartzanas, T., Boulard, T., Kittas, C.: Effect of Vent Arrangement on Windward Ventilation of a Tunnel Greenhouse. J. Biosystems Engineering 88(4), 479-490 (2004)

10. Boularda, T., Royb, J.C., Fatnassi, H., et al.: Computer fluid dynamics prediction of climate and fungal spore transfer in a rose greenhouse. J. Computers and Electronics in Agriculture 74(2), 280-292 (2010) 